\title{
sciendo
}

\author{
Current Issues in Pharmacy and Medical Sciences
}

Formerly ANNALES UNIVERSITATIS MARIAE CURIE-SKLODOWSKA, SECTIO DDD, PHARMACIA

journal homepage: http://www.curipms.umlub.pl/

\section{Chemical constituents of Algerian mandarin (Citrus reticulata) essential oil by GC-MS and FT-IR analysis}

\author{
Hicham Boughendjioua $^{1 \star}{ }^{\star}$, Nour El Houda Mezedjeri ${ }^{2}$, Ilhem Idjouadiene $^{2}$
}

\begin{abstract}
${ }^{1}$ Department of Natural Sciences, Higher School of Professors for Technological Education, Skikda, Algeria
2 Department of Biology, University of Skikda, Algeria
\end{abstract}

\begin{tabular}{l}
\hline ARTICLE INFO \\
\hline Received 20 March 2020 \\
Accepted 04 August 2020 \\
\hline Keywords: \\
mandarin, \\
Citrus reticulata, \\
essential oil, \\
gas chromatography-mass \\
spectrometry analysis (GCMS), \\
Fourier-Transform Infrared \\
Spectroscopy (FTIR).
\end{tabular}

\begin{abstract}
Medicinal plants are potential sources of natural compounds with biological activities and therefore attract the attention of researchers worldwide. Citrus oils are a complex mixture of more than a hundred components of differing chemical natures. Qualitative and quantitative analysis by gas chromatography coupled with mass spectrometry (GCMS) of the Citrus reticulata essential oil collected from El Hadaïk, Skikda City (Algeria), identified 28 compounds representing a total of $99.41 \%$. The essential oil is constituted mainly of: D-Limonene (85.10\%), Sabinene (2.49\%), Linalyl acetate (2.00\%), Copaene $(1.80 \%)$ et $\alpha$-Pinene $(1.75 \%)$ totaling approximately $93.14 \%$. The essential oil was also analyzed by Fourier transform infrared spectroscopy analysis (FTIR). FTIR spectroscopy allowed us to identify 10 volatile compounds and indicated that the functional groups of the essential oils are $\mathrm{C}-\mathrm{H}$ (Alkene), $\mathrm{C}-\mathrm{H}$ (aromatic) and $\mathrm{C}=\mathrm{C}$. The obtained results have shown that the essential oil can be fully utilized for pharmacy, cosmetology and industry.
\end{abstract}

\section{INTRODUCTION}

The genus Citrus (Rutaceae) is one of the ancient, most traded and most popular crops. The earliest records of its cultivation date back to $2100 \mathrm{BC}$ [1]. The origin of Citrus is still controversial; however, it is believed to have come from Southeast Asia Mandarins that have their origin in China and are native to the countries of South East Asia and the Philippines. The fruit spread through Asia, and, eventually in the $19^{\text {th }}$ century, to the Western world. Today, it is cultivated in Mediterranean or subtropical climates around the globe. There are several varieties of this fruit, including tangerines, a deep orange-red hybrid species originating from Tangier and the clementine from Algeria [2]. Interestingly, essential oil is the most vital by-product of Citrus processing. Citrus essential oils are broadly used as natural food additives in several food and beverage products [3] because they have been classified as generally recognized as safe (GRAS) [4]. Furthermore, Citrus essential oils are used as natural preservatives due to their broad spectrum of biological activities, including antimicrobial and antioxidant effects [5]. Because of their high economic importance, numerous studies have investigated the chemical composition of the peel, leaf, and flower essential oils of different Citrus species. It is worth noting that there is a great variation in the chemical

\footnotetext{
* Corresponding author

e-mail: boughendjioua.hicham@yahoo.com
}

composition of Citrus oils due to differences in origin, genetic background, season, climate, age, ripening stage, method of extraction, etc. [6-10]. Roughly 700 to $800 \mathrm{~kg}$ of mandarin fruit is needed to produce one kilo of essential oil.

There are three kinds of essential oil; green, yellow and red, all derived from the same fruit, but at different stages of maturity. Green mandarin oil is generally sharper and with more of a "peel" note compared to red mandarin. The volatile components are presented in Figure 1. Sweet orange, bitter orange, mandarin and grapefruit essential oils are rich in monoterpenes, with the major component being d-limonene (65.3-95.9\%) [5].

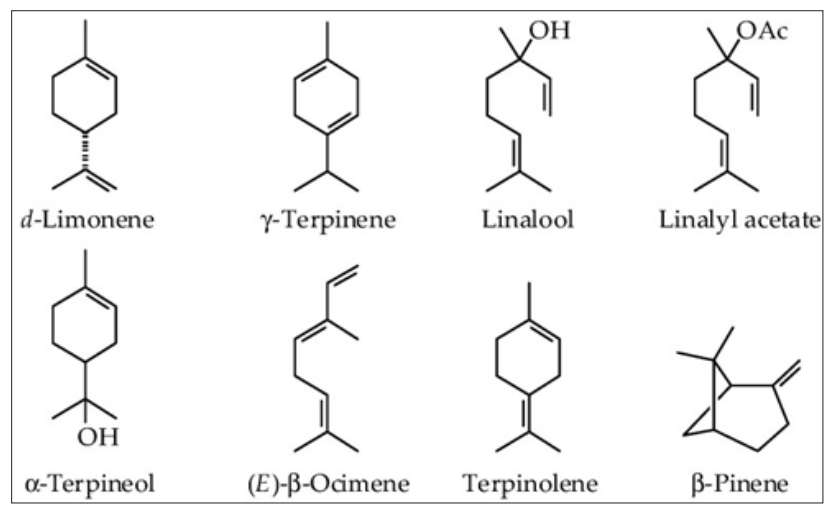

Figure 1. Chemical structures of volatile components in Citrus essential oils [11] 
Infrared (IR) spectrometry offers researchers and breeders an alternative approach that is robust and rapid for assessing essential oil content. The majority of the carbon-based molecules in plants are highly active in the IR. At its simplest, mid-IR spectroscopy is a useful analytical approach in its own right that provides structural information on samples of pure compounds [12].

Spectroscopy is based on the study of the interactions between matter and electromagnetic radiation. This radiation consists of a particle beam having an undulating motion. Together, all electromagnetic radiation forms the electromagnetic spectrum. In the spectrum, four regions are discernible: X-rays, ultraviolet (UV), visible and infrared (IR). The emphasis will be on infrared (IR) spectroscopy because spectrum analysis in this region allows us to follow a reaction process, determine the dosage of a compound, check the purity of a product and identify an unknown. Moreover, it is an inexpensive and easy to use process. Hence, IR spectroscopy is the most widely used spectral method used by chemists. The principle is based on molecular vibrations. The energy emitted as photons can be absorbed by the material causing vibration in the molecules. This vibration changes the angle and the distance between the atoms. When the molecule returns to its original form, energy will be released as heat. The absorption and release of energy by the molecule will be recorded by the apparatus and translated into a band spectrum. The analysis of this spectrum makes it possible to obtain the necessary information of the material analyzed [13].

The study of the physiologically active components of Citrus and their contribution to human health is a growing research field. The main objective of the present study is to analyze the various phytochemical constituents of Algerian Mandarin (Citrus reticulata) essential oil by using GCMS and FTIR analysis, and to show the advantages of FTIR for direct and rapid test methods. This methodology can also be applied to identify metabolomic indicators, and, based on their specificities, to establish a faster traceability and quality control for discrimination of Citrus reticulata essential oil.

\section{MATERIALS AND METHODS}

\section{Plant material}

$1488.4 \mathrm{~g}$ of the tested sample was obtained from a private farm located in the region in El Hadaïk (Skikda city, NorthEast of Algeria). Plant harvesting was carried in October and December 2018. The upper part of the pericarp was harvested from fresh fruit, this choice was justified by the richness of zest in essential oils compared to other parts of the fruit [14]. The plant was taxonomically identified at Department of Natural Sciences, High School Professors Technological Education, Skikda (Algeria) by Dr. Hicham Boughendjioua. Specie name was according to International Plant Name Index (IPNI).

\section{Isolation of the essential oil}

The essential oils was obtained by cold expression (physical process). This is a simple approach to citrus fruit processing [15], and this extraction does not change the composition of the oil [16]. The product obtained is called 'gasoline', because it does not undergo any chemical modification $[15,17]$. The obtained essential oil was stocked at $4^{\circ} \mathrm{C}$, in the presence of anhydrous sodium sulfate, until further analyses.

\section{Gas chromatography-mass spectrometry analysis (GCMS)}

The experiment was performed by using a Perkin Elmer Clarus 500 gas chromatographer equipped with an Elite-5 ms capillary column ( $30 \mathrm{~nm} \mathrm{X} 0.25 \mathrm{~mm} \mathrm{X} 0.25 \mu \mathrm{m}$ ), as well as a mass detector 'Turbo Mass Gold' (PerkinElmer, USA) operating in EI mode. The column temperature was set at $60^{\circ} \mathrm{C}$ initially (maintained for $3 \mathrm{~min}$ ), which was then increased to $160^{\circ} \mathrm{C}$ at a rate of $4^{\circ} \mathrm{C} / \mathrm{min}$ and finally to $280^{\circ} \mathrm{C}$ at a rate of $10^{\circ} \mathrm{C} / \mathrm{min}$ (maintained for $5 \mathrm{~min}$ ). Injector, interface and ion-source were kept at 270,250 and $200^{\circ} \mathrm{C}$, respectively. The carrier gas was helium with a constant flow rate of $1.0 \mathrm{~mL} / \mathrm{min}$. To the experimental conditions of the mass spectrometer, electron impact $(\mathrm{EI}+)$ mass spectra were recorded at $70 \mathrm{eV}$. Splitting ratio was 10:1. Scan was set at $0.2 \mathrm{scan} / \mathrm{s}$ from $\mathrm{m} / \mathrm{z} 35$ to $500 \mathrm{amu}$. The samples were diluted in n-hexane prior to injection to obtain the appropriate peak intensity. Injection volume of the sample was $0.2 \mu 1$. The analysis of the chemical composition of essential oil by GCMS was made at the Regional Police Scientific Laboratory (Constantine, Algeria). Retention indices for all compounds were determined according to the Van den Dool approach [18], using n-alkanes $\left(\mathrm{C}_{9}-\mathrm{C}_{24}\right)$ as standards. Identification of the components was based on comparison of their MS with those of the Wiley library and those described in the literature [19].

\section{Fourier-transform infrared spectroscopy analysis (FTIR)}

FTIR was performed with a PERKIN ELMER (universal ATR Sampling Accessory) apparatus, the operating conditions were as follows: technique: ATR, analysis range: 4000-600 $\mathrm{cm}^{-1}$. The results are directly compared with those of the internal bibliography of the apparatus; 01. Euclidean, 02. PSU/peak, 03. MIX PSU, 04. Peak Match, 05. PEAK/psu, 06. MIX PEAK. The comparison was made between crude essential oil and the Limonene (standard of the Euclidean internal library). The FTIR analysis was performed at the Regional Police Scientific Laboratory (Constantine, Algeria).

\section{RESULTS AND DISCUSSION}

\section{Chemical constituents of essential oil using GCMS}

We observed that minimum essential oil yield $(0.1 \%)$ was obtained when fruits were immature (during October). As the fruit samples matured, the oil yield increased. In December, the essential oil yield rose to $0.2 \%$. The chromatographic analyse resulted in the identification of 28 compounds representing a total of $99.41 \%$. The essential oil of Citrus reticulata consists mainly of: D-Limonene $(85.10 \%)$, Sabinene $(2.49 \%)$, Linalyl acetate $(2.00 \%)$, Copaene $(1.80 \%)$ et a.-Pinene (1.75\%) totaling approximately $93.14 \%$ (Table 1 and Figure 2). These results were not in agreement with previous research reported for the same plant. 
Table 1. Chemical composition of Citrus reticulata essential oil

\begin{tabular}{|c|c|c|c|c|}
\hline No. & Compounds & $\begin{array}{c}\text { Retention } \\
\text { indices }\end{array}$ & \begin{tabular}{|} 
Retention time \\
$(\mathrm{min})$
\end{tabular} & $\%$ \\
\hline 1. & a-Pinene & 925 & 4.58 & 1.75 \\
\hline 2. & $\beta$-Phellandrene & 970 & 5.64 & 0.89 \\
\hline 3. & Sabinene & 974 & 6.16 & 2.49 \\
\hline 4. & $\beta$-Myrcene & 980 & 6.20 & 0.80 \\
\hline 5. & Octanal & 985 & 6.54 & 0.10 \\
\hline 6. & Caprylaldehyde & 988 & 7.43 & 0.12 \\
\hline 7. & 1,2-Methyleneheptane & 990 & 7.49 & 0.13 \\
\hline 8. & Propylcyclopentane & 993 & 7.52 & 0.15 \\
\hline 9. & Hendecanol & 995 & 7.55 & 0.16 \\
\hline 10. & Octamethylene & 1000 & 7.62 & 0.18 \\
\hline 11. & Gentanol & 1005 & 7.65 & 0.19 \\
\hline 12. & Heptanol & 1010 & 7.72 & 0.21 \\
\hline 13. & D-Limonene & 1022 & 7.73 & 85.10 \\
\hline 14. & p-menthadiene & 1033 & 7.78 & 0.14 \\
\hline 15. & Tricyclene & 1040 & 8.28 & 0.90 \\
\hline 16. & $\mathrm{y}$-Terpinene & 1043 & 8.76 & 0.11 \\
\hline 17. & a-Humulene & 1050 & 9.19 & 0.06 \\
\hline 18. & Linalool & 1086 & 9.57 & 0.08 \\
\hline 19. & Linalyl acetate & 1233 & 9.63 & 2.00 \\
\hline 20. & Citronellal & 1240 & 11.39 & 0.10 \\
\hline 21. & Terpinen-4-ol & 1272 & 12.17 & 0.14 \\
\hline 22. & (Z)- $\beta$-ocimenol & 1290 & 12.63 & 0.38 \\
\hline 23. & Decanal & 1303 & 13.16 & 0.45 \\
\hline 24. & Copaene & 1362 & 13.20 & 1.80 \\
\hline 25. & a-Cubebene & 1480 & 18.74 & 0.08 \\
\hline 26. & $\beta$-Cubebene & 1558 & 19.26 & 0.09 \\
\hline 27. & Dodecanal & 1700 & 19.88 & 0.10 \\
\hline 28. & a-Sinensal & 1750 & 29.57 & 0.71 \\
\hline & \multicolumn{3}{|l|}{ Total } & 99.41 \\
\hline
\end{tabular}

In four analyzed Citrus oils, limonene was the most abundant component. Mandarin: limonene $(74.7 \%)$ and $\gamma$-terpinene (15.7\%); lemon: limonene $(69.9 \%)$ and $\beta$ - pinene (11.2\%); orange: limonene (94.9\%) and $\beta$-myrcene $(1.16 \%)$; grapefruit: limonene $(96.2 \%)$ and myrcene $(1.4 \%)$ [20]. Essential oil from the peel of fully matured Citrus reticulata Blanco isolated by hydrodistillation were analyzed by GC and GC-MS. Thirty-seven different components were identified, constituting approximately $\geq 99 \%$ of the oil. The major components were limonene (46.7\%), geranial $(19.0 \%)$, neral $(14.5 \%)$, geranyl acetate $(3.9 \%)$, geraniol (3.5\%), $\beta$-caryophyllene $(2.6 \%)$, nerol $(2.3 \%)$, neryl acetate $(1.1 \%)[21]$.

The chemical composition of hydrodistilled oils obtained from the leaves of six Citrus reticulata Blanco (mandarin) cultivars grown in Nigeria were examined by GC and GC/ MS, the result of their chemical composition was further submitted to cluster analysis. Fifty-seven constituents were characterized accounting for $88.2-96.7 \%$ of the total oils. Sabinene, g-terpinene, p-cymene, d-3-carene and (E)b-ocimene were observed in great variability in all the oils. Other constituents include linalool, myrcene, terpinen-4-ol

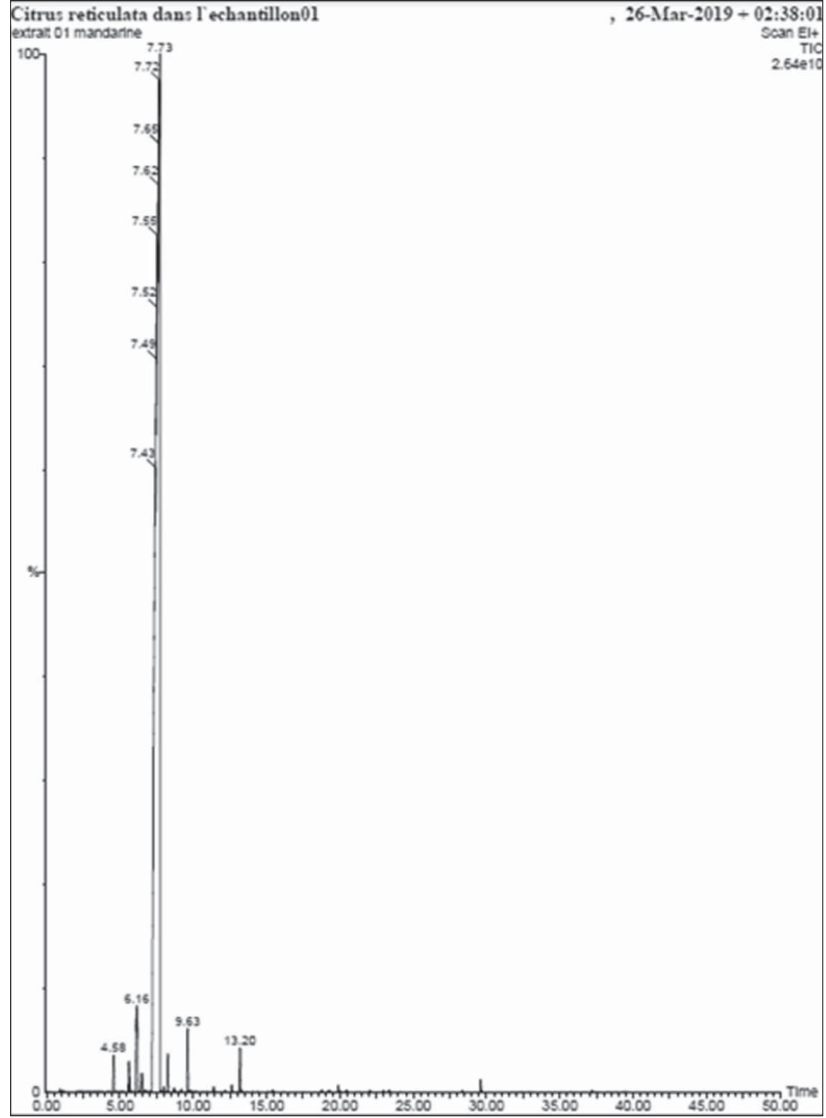

Figure 2. Typical GCMS chromatogram of Citrus reticulata essential oil

and cissabinenehydrate. In addition, limonene, terpinolene, $\beta$-pinene, and $\alpha$-pinene were detected in appreciable concentrations. $\beta$-sinensal and $\alpha$-sinensal were isolated by preparative GC and characterized by one- and two-dimensional NMR techniques [22].

The great variability may have been due to several factors, among them the particular varieties studied, the geographical location, season and environmental factors, such as soil type and climate, genetic factors, processing and extraction method and the part of the plant used for extracting the oil [20].

\section{Determination of the functional groups present using FTIR}

Fourier-transform infrared spectroscopy is one of the most widely employed techniques for functional groups identification. Figure 3 and Table 2 show the infrared spectra and the characteristic bands observed in Citrus reticulata essential oil in the range of 4000-600 $\mathrm{cm}^{-1}$ :

Table 2. Links present in the molecule of Limonene

\begin{tabular}{|l|c|c|}
\hline $\begin{array}{c}\text { Present links } \\
\text { in Limonene }\end{array}$ & $\begin{array}{c}\text { Theoretical frequency } \\
\text { of the band }\left(\mathrm{cm}^{-1}\right)\end{array}$ & $\begin{array}{c}\text { Presence of the band } \\
\text { in the spectrum }\end{array}$ \\
\hline C-H (Alkene) & $3100-3000$ & Yes \\
\hline C-H (aromatic) & $3150-3050$ & Yes \\
\hline C=C & $1600-1680$ & Yes \\
\hline
\end{tabular}




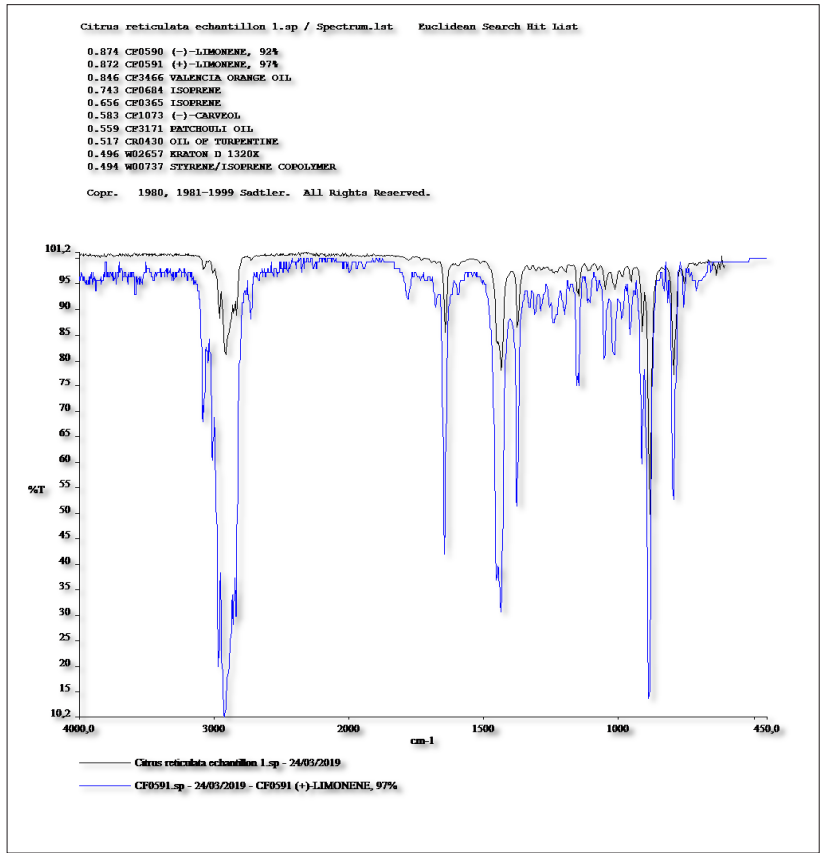

Figure 3. FTIR of Citrus reticulata essential oil compared to the bibliography

The spectrum of Limonene, as well as that of pure essential oils had several similarities (Figure 3) Unfortunately, no "fingerprint" of the extracted oil coincided with that of pure essential oils or Limonene. Among the ten compounds revealed by FTIR: (1). (-) - limonene, 92\%, (2). (+) - limonene, $97 \%$, (3). Valencia orange oil, (4). Isoprene, (5). Isoprene, (6). (-) - carveol, (7). Patchouli oil, (8). Oil of turpentine, (9). Kraton D 1320X, (10). Styrene / isoprene copolymer.

On the other hand, the complete and detailed study of a spectrum is an operation rarely practiced in current interpretation because of the complexity of the analysis. It is, therefore, often limited to the identification of functional groups through the location of the different bands on the spectrum. The spectrum presents characteristic bands at $1600-1680 \mathrm{~cm}^{-1}$ corresponding to $\mathrm{C}=\mathrm{C}$; the signals appearing between $3100-3000 \mathrm{~cm}^{-1}$ and $3150-3050 \mathrm{~cm}^{-1}$ are caused by the asymmetrical and symmetrical stretching vibrations of $\mathrm{C}-\mathrm{H}$ groups (Figure 4 and 5).

It should be noted that Alkane C-H bonds are fairly ubiquitous and therefore usually less useful in determining structure. For C-H Stretch with characteristic absorption $\left(\mathrm{cm}^{-1}\right)$ of 3100-3010 (m), absorption peaks above $3000 \mathrm{~cm}^{-1}$ are frequently diagnostic of unsaturation [23].According to Elzey et al., (2016) [24] the FTIR specter of the pure essential oil of Lemon (from the same family of the Mandarin), shows the expected characteristic C-H stretch $\left(\sim 2900 \mathrm{~cm}^{-1}\right)$, $\mathrm{C}=\mathrm{O}$ stretch $\left(\sim 1700 \mathrm{~cm}^{-1}\right)$, broad O-H stretch $\left(\sim 3400 \mathrm{~cm}^{-1}\right)$, and $\mathrm{C}-\mathrm{O}$ stretch $\left(\sim 1100 \mathrm{~cm}^{-1}\right)$ of terpenoid components. The compositions and constituents of essential oils may vary and highly depend on the geochemistry of the soil where it is cultivated. In general, essential oils are made up of terpenes such as terpineol, cineole, citronellal, and others.

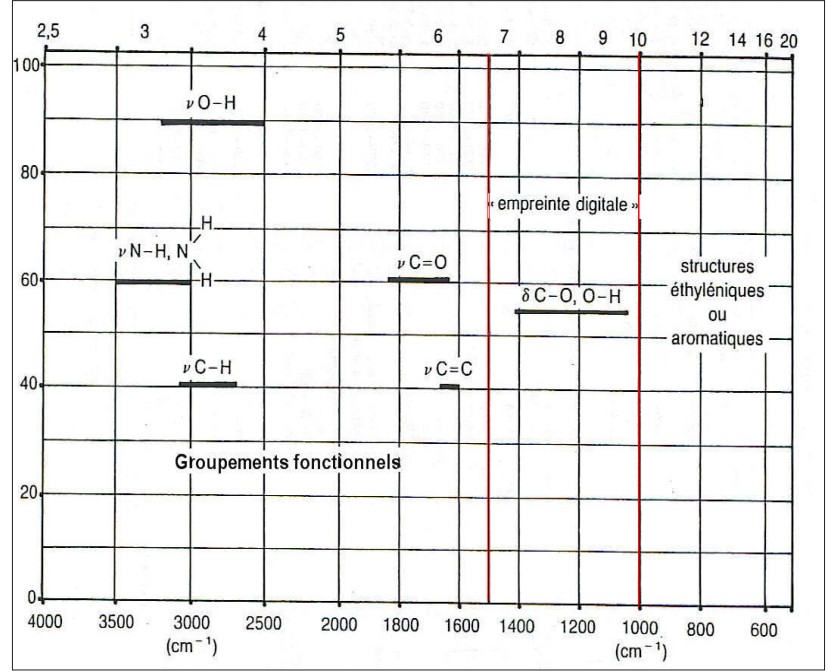

Figure 4. Graphs of IR spectroscopy

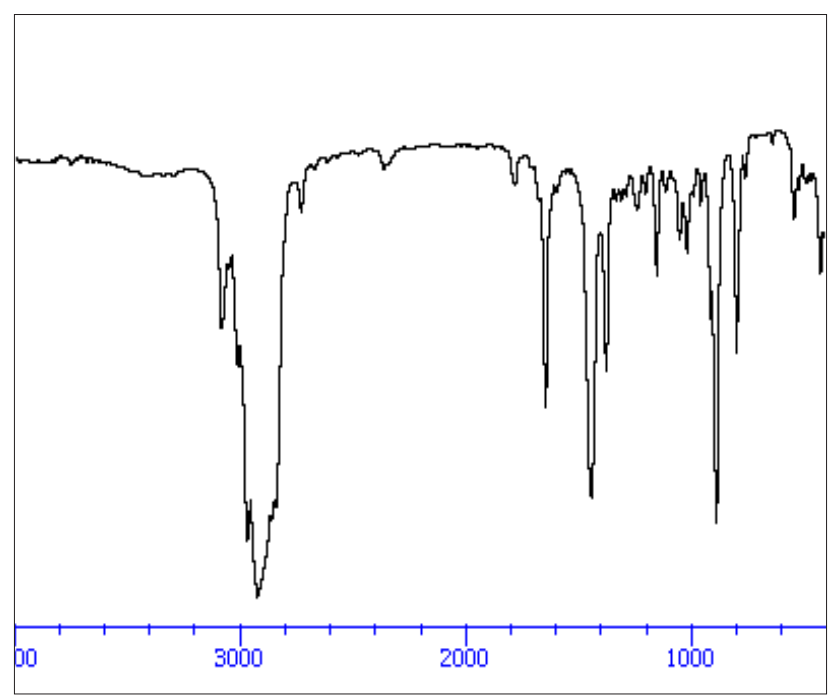

Figure 5. IR diagram of d Limone

\section{CONCLUSION}

An attempt has been made in this work to study the chemical constituents of Algerian Mandarin (Citrus reticulata) essential oil by gas chromatography coupled with mass spectrometry (GCMS), as well as the functional derivatives by observing the position and relative intensities of the band in Fourier transform infrared spectroscopy analysis (FTIR). The spectral analysis indicated that the specific functional groups. FTIR spectroscopy technique showed that the presence of functional groups which can be isolated and further screened for different kind of biological activities depending their therapeutic uses. Further research will be needed to discover the structural analysis of the compound. The intent is to use different analytical methods such as NMR and Mass spectrophotometer. Finally, this technique allows a reduced time of analysis (minimal sample preparation) and has the advantage of being more chemical sustainable since there is no need of organic solvents for extraction.

\section{CONFLICT OF INTEREST}

The authors declare that they have no conflict of interest. 


\section{ORCID iDs}

Hicham Boughendjioua (Dhttps://orcid.org/0000-0001-8640-9904

\section{REFERENCES}

1. Moore GA. Oranges and lemons: Clues to the taxonomy of Citrus from molecular markers. Trends Genet. 2001;17:536-40.

2. Mabberley DJ. Citrus (Rutaceae): A review of recent advances in etymology, systematics and medical applications. Blumea. 2004;49: 481-98.

3. Ferhat MA, Meklati BY, Smadja J, Chemat F. An improved microwave Clevenger apparatus for distillation of essential oils from orange peel. J Chromatogr A. 2006;1112:121-6.

4. Tisserand R, Young R. Essential Oil Safety. $2^{\text {nd }}$ ed. Elsevier; New York; 2014:784.

5. Mitropoulou G, Fitsiou E, Spyridopoulou K, Tiptiri-Kourpeti A, Bardouki H, Vamvakias M, et al. Citrus medica essential oil exhibits significant antimicrobial and antiproliferative activity. LWT Food Sci Technol. 2017;84:344-52

6. Caccioni DR, Guizzardi M, Biondi DM, Renda A, Ruberto G. Relationship between volatile components of citrus fruit essential oils and antimicrobial action on Penicillium digitatum and Penicillium italicum. Int J Food Microbiol. 1998;43:73-9.

7. De Pasquale F, Siragusa M, Abbate L, Tusa N, De Pasquale C, Alonzo G. Characterization of five sour orange clones through molecular markers and leaf essential oils analysis. Sci Hortic. 2006; 109:54-9.

8. Dosoky NS, Stewart CD, Setzer WN. Identification of essential oil components from Conradina canescens. Am J Essent Oil Nat Prod. 2014;2:24-8.

9. Dosoky NS, Moriarity DM, Setzer WN. Phytochemical and biological investigations of Conradina canescens. Nat Prod Commun. 2016;11:25-8.

10. da Silva JK, da Trindade R, Moreira EC, Maia JGS, Dosoky NS, Miller RS, et al. Chemical diversity, biological activity, and genetic aspects of three Ocotea species from the Amazon. IJMS. 2017;18:1081.
11. Dosoky NS, Setzer WN. Biological Activities and Safety of Citrus spp. Essential Oils. IJMS. 2018;19(7):1966.

12. Hsu CPS. Infrared spectroscopy. In: Handbook of instrumental techniques for analytical chemistry edited by Frank A. Settle. Prentice Hall: Upper Saddle River; 1997:247-283.

13. Meskine M, Ouardi O. Analyse des fréquences rovibrationnelles des molécules octaédriques. Revue Algérienne de Physique. 2010;04:62-8.

14. Robert A, Lobstein A. Plantes aromatiques: épices, aromates, condiments et huiles essentielles. Paris : Éd. Tec \& doc; 2005:522.

15. Roux D. Conseil en aromathérapie. 2ème édition, pro officina (Rueil Malmaison). France; 2008:187.

16. Chiej R. Green Guide, Medicinal plants. Edition Solar; 1982:331.

17. Basil A, Jimenez-carmonna MM. Extraction of rosemary by superheated water. J Food Chem. 1998;46:5205-9.

18. Van Den Dool H, Kratz PD. A generalization of the retention index system including linear temperature programmed gas-liquid partition chromatography. J Chromatogr A. 1963;11:463-7.

19. Davies NW. Gas chromatographic retention indices of monoterpenes on methyl silicone and Carbowax $20 \mathrm{M}$ phases. J Chromatogr A. 1990;503:1-24.

20. Viuda-Martos M, Ruiz-Navajas Y, Fernández-López J, Pérez-Álvarez JA. Chemical composition of mandarin (C. reticulata L.), grapefruit (C. paradisi L.), lemon (C. limon L.) and orange (C. sinensis L.) Essential Oils. J Essen Oil Bear Pl. 2009;12(2):236-43.

21. Chutia M, Deka Bhuyan P, Pathak MG, Sarma TC, Boruah P. Antifungal activity and chemical composition of Citrus reticulata Blanco essential oil against phytopathogens from North East India. LWT Food Sci Technol. 2009;42(3):777-780.

22. Kasali AA, Lawal OA, Abanikannda OTF, Olaniyan AA, Setzer WN. Citrus Essential Oils of Nigeria Part IV: Volatile Constituents of Leaf Oils of Mandarins (Citrus reticulata Blanco) From Nigeria. Rec Nat Prod. 2010;4(3):156-62.

23. Dias RF. Spectroscopy: How do we know what organic molecules look like? Org Chem. 2005;48-58.

24. Elzey B, Norman V, Stephenson J, Pollard D, Fakayode SO. Purity analysis of adulterated essential oils by FT-IR spectroscopy and partial-least-squares regression. Spectroscopy. 2016;31(8):26-37. 